Check for updates

Cite this: Mater. Adv., 2021, 2, 5471

Received 24th May 2021, Accepted 7th July 2021

DOI: $10.1039 / \mathrm{d} 1 \mathrm{ma00461a}$

rsc.li/materials-advances

\section{Gallium nanoparticles as novel inhibitors of Aß40 aggregation}

\author{
Kyabeth M. Torres, ${ }^{a}$ Ambar S. Delgado, ${ }^{a}$ Erika R. Serrano, ${ }^{b}$ Nitza V. Falcón-Cruz, ${ }^{b}$ \\ Anamaris Meléndez, ${ }^{c}$ Idalia Ramos, (D) c Deguo Du (D) *d and Rolando Oyola (iD *b
}

\begin{abstract}
Alzheimer's disease (AD) has been consistently related to the formation of senile amyloid plaques mainly composed of amyloid $\beta$ (AB) peptides. The toxicity of $A \beta$ aggregates has been indicated to be responsible for $A D$ pathology. One scenario to decrease $A \beta$ toxicity is the development of effective inhibitors against $A \beta$ amyloid formation. In this study, we investigate the effect of gallium nitride nanoparticles (GaN NPs) as inhibitors of $A \beta 40$ amyloid formation using a combination of biophysical approaches. Our results show that the lag phase of A 340 aggregation kinetics is significantly retarded by GaN NPs in a concentration dependent manner, implying the activity of GaN NPs in interfering with the formation of the crucial nucleus during $A \beta$ aggregation. Our results also show that GaN NPs can reduce the amyloid fibril elongation rate in the course of the aggregation kinetics. It is speculated that the high polarization characteristics of GaN NPs may provoke a strong interaction between the particles and A $\beta 40$ peptide and in this way decrease self-association of the peptide monomers to form amyloids.
\end{abstract}

\section{Introduction}

Alzheimer's disease (AD) is a progressive, irreversible, and currently incurable neurodegenerative disorder characterized by neuronal loss, memory impairment, and cognitive decline., As the leading cause of dementia in a rapidly aging population, $\mathrm{AD}$ is a growing threat to global health, economies, and society in general. One possible pathway to develop AD has been linked to the formation of senile plaques due to the aggregation of a group of key amyloid- $\beta(\mathrm{A} \beta)$ peptides, e.g., $\mathrm{A} \beta 40$ and $\mathrm{A} \beta 42$, that are formed from the cleavage of the transmembrane amyloid precursor protein (APP) by $\beta$ - and $\gamma$-secretases. ${ }^{2-4}$ Amyloid formation of $A \beta$ is typically viewed as a nucleated polymerization process, manifested by an initial lag phase in which the oligomeric nuclei are formed, followed by a rapid growth phase during which the nuclei grow by the addition of monomers to form fibrillar structures. ${ }^{5,6}$ Moreover, amyloid oligomers have also been shown to form hetero-oligomers by interacting with its isoforms or other proteins. ${ }^{5,7}$ Therefore great effort has been devoted to characterize oligomers to better understand the

\footnotetext{
${ }^{a}$ University of Puerto Rico-Humacao, Department of Biology, Call Box 860, Humacao 00792 PR, USA

${ }^{b}$ University of Puerto Rico-Humacao, Department of Chemistry, Call Box 860, Humacao 00792 PR, USA. E-mail: rolando.oyola@upr.edu

${ }^{c}$ University of Puerto Rico-Humacao, Department of Physics \& Electronics, Call Box 860, Humacao 00792 PR, USA

${ }^{d}$ Florida Atlantic University, Department of Chemistry \& Biochemistry,

Boca Raton, 33431, FL, USA. E-mail: ddu@fau.edu
}

amyloid formation mechanism and conceive plausible therapeutic alternatives. $^{4,6}$

One of the plausible therapeutic strategies for treating the disease is to inhibit the formation of toxic $A \beta$ aggregate species. As such, a wide variety of amyloid inhibitors that can prevent the formation of $\mathrm{A} \beta$ aggregates, e.g., small organic compounds and designed peptides, have been reported. ${ }^{2,3,8-10}$ Also, recent studies have demonstrated that various nanoparticles (NPs) can either completely or partially inhibit $\mathrm{A} \beta$ fibril formation, due to their interactions with $A \beta .^{11-13}$ NPs have been used as an important build block to construct new $A \beta$ inhibitors using surface modification and changes in morphology of the particles. $^{14}$

Different substrates have been used to establish NP cores for the development of efficient NPs for therapeutic applications. The common NP formulations employed in the diagnosis and therapeutic studies of AD include polymeric NPs, gold NPs (Au NPs), gadolinium NPs, selenium NPs, protein-based NPs, and polysaccharide-based NPs. ${ }^{15}$ For example, Liao et al. showed that bare $\mathrm{Au}$ NPs inhibited $\mathrm{A} \beta$ fibrillation, leading to the formation of fragmented fibrils and spherical oligomers. ${ }^{16}$ These authors reasoned that the negative surface potential of $\mathrm{Au}$ NPs is an important factor for the inhibition of $\mathrm{A} \beta$ amyloid fibril formation. Similarly, Yin et al. demonstrated that selenium NPs not only effectively inhibit $A \beta$ aggregation but could disaggregate preformed $\mathrm{A} \beta$ fibrils into non-toxic amorphous oligomers. ${ }^{17}$ Family III nitrides, particularly gallium, aluminium, and indium nitrides, have gained considerable interest for use as transducing materials in biosensors. ${ }^{18}$ Specifically, 
gallium nitride ( $\mathrm{GaN})$ is a semiconductor material with wurtzite crystal structure that has a wide $(3.4 \mathrm{eV})$ band gap and is widely used in ultraviolet-blue light emitting diodes, photodetectors and lasers. ${ }^{19}$ In addition, GaN demonstrates good biocompatibility and aqueous stability in conditions relevant to biological applications. ${ }^{20-22}$ Therefore, GaN has also been used in various biological applications. Braniste et al. reported the uptake of GaN NPs by porcine endothelial cells, ${ }^{23}$ and their results suggested that the uptake of the particles by the cells is strongly dependent upon whether the GaN NPs are fixed to a substrate surface or free floating in the medium. The endothelial cells growing on surfaces functionalized with GaN NPs demonstrated excellent adhesion and proliferation, suggesting good biocompatibility of the nanoparticles. The same research group expanded their studies and demonstrated that GaN/Fe-based nanoparticles exhibiting magnetic properties can be taken up by endothelial cells and stored within vesicles. ${ }^{24}$ In addition, Hofstetter et al. performed an investigation of the effects of differently treated GaN surfaces on mouse fibroblast cell proliferation and growth dynamics. ${ }^{25}$ Their results suggest that GaN does not require specific surface treatments to be biocompatible and that cell signalling is not affected by GaN-cell interactions. Jewett et al. demonstrated that functionalized and etched GaN surfaces are stable in aqueous environments and leach a negligible amount of $\mathrm{Ga}$ in solution even in the presence of hydrogen peroxide. ${ }^{26}$ Also, GaN surfaces in cell culture did not interfere with nearby cell growth, and the etched GaN promoted the adhesion of cells better than the etched silicon surfaces. On the other hand, $\mathrm{Ga}^{3+}$ can interfere with the iron metabolism in cells leading to apoptosis. ${ }^{27}$ This was attributed to the similar ionic radius of $\mathrm{Ga}^{3+}$ and $\mathrm{Fe}^{3+}$ and $\mathrm{Ga}^{3+}$ being less electroactive than $\mathrm{Fe}^{3+}$ in the iron metabolic processes. ${ }^{28}$

While GaN has emerged as a promising candidate for biointerfacing, ${ }^{29}$ to the best of our knowledge, the potential use of $\mathrm{GaN}$ as an inhibitor of aggregation of amyloidogenic proteins including $\mathrm{A} \beta$, has not been explored. Since previous studies have shown that GaN can interact with various cellular components, it is possible that GaN NPs are able to interact with $\mathrm{A} \beta$ peptide and in consequence affect the aggregation behaviour. In this study, we investigate the effect of GaN NPs on the aggregation of $\mathrm{A} \beta 40$ in vitro using a combination of biophysical approaches. In comparison to $\mathrm{A} \beta 42, \mathrm{~A} \beta 40$ is less toxic to neurons and exerts a more moderate aggregation propensity and thus is appropriate for a sophisticated investigation of the properties of aggregation kinetics. Our results demonstrate that GaN NPs markedly affects the characteristics of A $\beta 40$ oligomerization and fibrillization. It is expected that further molecular modification of the surface characteristics such as the charge properties of GaN NPs may be an approach for designing potent NP inhibitors against protein amyloidogenesis.

\section{Experimental}

\section{Materials}

A $\beta 40$ was obtained from Life Tein Company (NJ, USA). Certified analysis of the peptide established that the purity was higher than $>95 \%$ with a formula weight of 4329.9 . The peptide was used as received. Gallium nitrate hydrate was obtained from Sigma-Aldrich (USA) with $>99.9 \%$ purity trace metals basis. Congo red (CR) with high purity was obtained from Calbiochem (UK). Thioflavin $\mathrm{T}$ (ThT) was obtained from Sigma-Aldrich (USA). Other solvents and reagents were obtained from either Sigma-Aldrich (USA) or Fisher Scientific (Cayey, PR) and used without further purification.

\section{Synthesis of GaN NPs}

The GaN NPs were synthesized according to previous reports. ${ }^{30-34}$ Briefly, $\mathrm{Ga}\left(\mathrm{NO}_{3}\right)_{3}$ was dissolved in nitric acid, the $\mathrm{pH}$ was adjusted to 8.2 with ammonium hydroxide and citric acid was added until the solution became clear. The resulting solution was dried and heated in a burnout furnace under air at $400{ }^{\circ} \mathrm{C}$ for 4 hours producing a $\mathrm{Ga}_{2} \mathrm{O}_{3}$ powder that was converted to $\mathrm{GaN}$ in a tube furnace at $900{ }^{\circ} \mathrm{C}$ under an $\mathrm{NH}_{3}$ gas flow for 3 hours to ensure complete conversion. ${ }^{31}$

\section{X-Ray diffraction (XRD) measurements}

The phase structures of the nanoparticle samples were identified using X-ray diffraction techniques using a Bruker D2 Phaser with $\mathrm{Cu} \mathrm{K} \alpha$ radiation (wavelength of the radiation, $\lambda=1.54 \AA$ ) operating at $30 \mathrm{kV}$ and $10 \mathrm{~mA}$. The incident beam passed through a $2.5^{\circ}$ Soller slit, a $0.6^{\circ}(1.0 \mathrm{~mm})$ divergence slit, a secondary $2.5^{\circ}$ Soller slit, a Ni filter, and a receiving slit of $0.2 \mathrm{~mm}$. After interaction with the sample, the diffracted beam was detected using a scintillation counter. The samples were analyzed utilizing a Bragg-Brentano geometry over a range of $5-85^{\circ} 2 \theta$ with a step size of $0.02^{\circ} 2 \theta$, with each step measured for one second. For all $\mathrm{XRD}$ measurements, the samples were prepared as self-supported pressed powders over PMMA specimen holders from Bruker. Data analysis was performed using the instrument software, which includes the spectral database. In addition, XRD is a convenient method for determining the mean size of single-crystal nanoparticles or crystallites in nanocrystalline bulk materials. ${ }^{35}$ The size of the synthesized nanoparticles was calculated using the Scherrer formula, $D=K \lambda / \beta \cos \theta$ where $D$ is the average grain size, $K$ is the shape factor (taken as 0.9 ), $\lambda$ is the $\mathrm{X}$-ray wavelength, $\beta$ is the peak width measured in radians as the full width at half of the maximum intensity, and the Bragg angle is $21.485^{\circ}$.

\section{Aß40 aggregation kinetics followed by thioflavin T (ThT) emission}

The $\mathrm{A} \beta 40$ peptide utilized in the kinetic aggregation assay was monomerized as described previously. ${ }^{36,37}$ Briefly, lyophilized A $\beta 40$ powder was dissolved in aqueous $\mathrm{NaOH}$ solution $(2 \mathrm{mM})$ and the $\mathrm{pH}$ was adjusted to $11 \mathrm{using}$ a $100 \mathrm{mM} \mathrm{NaOH}$ solution followed by sonicating the solution for 1 hour in an ice-cold water bath. The resulting solution was filtered through a $0.22 \mu \mathrm{m}$ filter and kept on ice before use. The concentration of the A $\beta 40$ stock solution was determined using tyrosine UV absorbance at $280 \mathrm{~nm}\left[\varepsilon_{280}=1280(\mathrm{M} \mathrm{cm})^{-1}\right]$ using an Agilent 8453 photodiode array spectrometer. The fluorescence kinetics were measured using a Fluoroskan Ascent microplate reader (Thermo-Nicolet, USA). Fibril formation of A $\beta 40$ was followed 
using the ThT fluorescence emission using filters (bandpass of $15 \mathrm{~nm}$ ) with an excitation of 435 and emission at $485 \mathrm{~nm}$, respectively. Each well contained $20 \mu \mathrm{M} \mathrm{A} \beta 40,20 \mu \mathrm{M}$ ThT, $150 \mathrm{mM} \mathrm{NaCl}$ in $50 \mathrm{mM}$ sodium phosphate buffer saline (PBS $\mathrm{pH}=7.4$ ) with or without GaN NPs in a total volume of $300 \mu \mathrm{L}$. The emission was measured through the bottom of the plate every five minutes with five seconds of gentle shaking (100 rpm) before readings at $37{ }^{\circ} \mathrm{C}$. The $\mathrm{A} \beta 40$ aggregation kinetic parameters were obtained from the average of at least three replicates. Fitting analysis was performed according to eqn (1); ${ }^{38}$

$$
F(t)=F_{0}+m_{0} t+\frac{F_{\mathrm{f}}+m_{\mathrm{f}} t}{\left(1+\exp ^{-k\left(t-\tau_{50}\right)}\right)}
$$

where $F(t)$ is the fluorescence at time $t, F_{0}$ and $m_{0}$ are the intercept and slope of the initial baseline, $F_{\mathrm{f}}$ and $m_{\mathrm{f}}$ are the intercept and slope of the final baseline, $k$ is the pseudo first order rate constant of aggregation, and $\tau_{50}$ is the time that is required to achieve half of the fluorescence amplitude between initial and maximum fluorescence. The lag time $\left(\tau_{\text {lag }}\right)$ is the time taken to reach the exponential phase of fibrillation and is given by $\tau_{50}-2 / k$. The fitting variables are $F_{0}, m_{0}, F_{\mathrm{f}}, m_{\mathrm{f}}, k$, and $\tau_{50}$. Curve fitting was done with MS Office 2016 using the Excel Solver tool.

\section{Congo red binding assay}

Congo red (CR) was dissolved in PBS at a concentration of $100 \mu \mathrm{M}$ and filtered through a $0.22 \mu \mathrm{m}$ membrane. The solutions were prepared by dilution of stock solutions to obtain the final concentrations of $5.0 \mu \mathrm{M}$ CR, $150 \mathrm{mM} \mathrm{NaCl}, 50 \mathrm{mM}$ PBS 7.4, and $\mathrm{A} \beta 40(15 \mu \mathrm{M})$ and incubated at $37{ }^{\circ} \mathrm{C}$ in a $10 \mathrm{~mm}$ pathlength optical quartz cell. The absorbance spectra were measured at certain times for the samples in triplicate. The incubation was run with gentle agitation. ${ }^{39}$

\section{Turbidity study}

The aggregation kinetics of $\mathrm{A} \beta 40$ was determined by monitoring the absorbance at $600 \mathrm{~nm}$ as reported previously. ${ }^{40,41}$ Samples were prepared as described in the CR binding studies but without the dye.

\section{Scanning electron microscopy (SEM)}

SEM images for nanoparticle characterization were acquired on a JEOL JSM-IT-100 with an Energy Dispersive Spectrometer operating at 25 or $30 \mathrm{kV}$. For amyloid fibrils, SEM images were acquired on an FEI Quanta 600 ESEM operating at $15 \mathrm{kV}$ at the Singh Center for Nanotechnology at the University of Pennsylvania. ${ }^{42}$ The sample solution was diluted 100 -fold with pure water. Subsequently, the diluted samples were placed on silicone and dried under nitrogen for $10 \mathrm{~min}$ before measuring the images.

\section{Results and discussion}

\section{Characterization of the synthesized GaN NPs}

The morphology of the synthesized GaN NPs was investigated using SEM. As shown in Fig. 1, the GaN NP samples dispersed

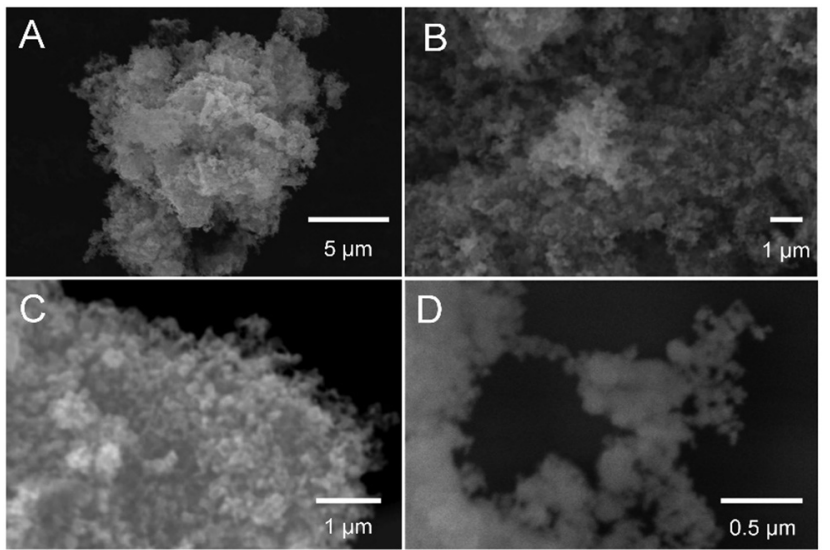

Fig. 1 SEM images of the synthesized GaN NPs. The images were measured at different kilovolts and magnifications: (A) $25 \mathrm{kV}, 5000 \times$; (B) $30 \mathrm{kV}$, $10000 \times$; (C) $30 \mathrm{kV}, 20000 \times$; and (D) $30 \mathrm{kV}, 50000 \times$

in water exhibit a typical crystallite morphology. The XRD spectrum of the GaN NPs resembles that previously reported by Chen et al., ${ }^{30}$ as shown in Fig. 2A. Specifically, the XRD pattern of the GaN NPs exhibits peaks at $2 \theta$ of $32.80,35.20$, and 37.26 and four other major peaks at 48.8, 58.2, 64.2, and 69.3 degrees, respectively. All these peaks can be indexed to a hexagonal (wurtzite) GaN structure. The GaN NP sizes determined using the Scherrer formula and the (110) peak at 58.2 degrees range from 6 to $12 \mathrm{~nm}$. The energy-dispersive spectrum (Fig. 2B) reveals that the elemental composition of the GaN NPs is $88.53,10.01$, and $1.46 \mathrm{w} / \mathrm{w} \%$ for gallium, nitrogen, and oxygen, respectively.

\section{Impact of GaN NPs on Aß40 aggregation kinetics measured using ThT fluorescence}

The formation of $A \beta 40$ amyloid aggregates starting from its monomeric state was studied using ThT fluorescence in the absence or presence of GaN NPs in sodium phosphate buffer (50 mM PBS buffer, $150 \mathrm{mM} \mathrm{NaCl,} \mathrm{pH} \mathrm{7.4).} \mathrm{ThT} \mathrm{is} \mathrm{an} \mathrm{envir-}$ onmentally sensitive fluorophore whose binding to amyloid fibrils dramatically increases its fluorescence quantum yield. ${ }^{43}$ Fig. 3 shows the time dependent ThT fluorescence intensity changes of the $\mathrm{A} \beta 40$ sample $(20 \mu \mathrm{M})$ in the absence or presence of GaN NPs. The kinetic curves are fitted using eqn (1) to obtain aggregation parameters such as $\tau_{50}$ and $\tau_{\text {lag }}$ (summarized in Fig. 4). In the absence of GaN NPs, the A 340 aggregation kinetics exhibit a typical sigmoidal shape, characteristic of a nucleation polymerization mechanism, ${ }^{44}$ which consists of a lag phase associated with nucleation, a fast growth phase related to the propagation of fibrils, and a final stationary phase related to the aggregated state. The kinetics exhibit a $\tau_{50}$ of 1044 minutes (Fig. 4), and a growth phase with a rate constant of $5.45 \times 10^{-3} \mathrm{~min}^{-1}$. To rule out the possibility that ThT can directly interact with the GaN NPs, causing its fluorescence intensity to change, we also performed control experiments where no $\mathrm{A} \beta 40$ is present. The results show that the ThT emission in the presence of GaN NPs does not only change with time (Fig. 3, curve f) and that the amplitude overlaps with the 

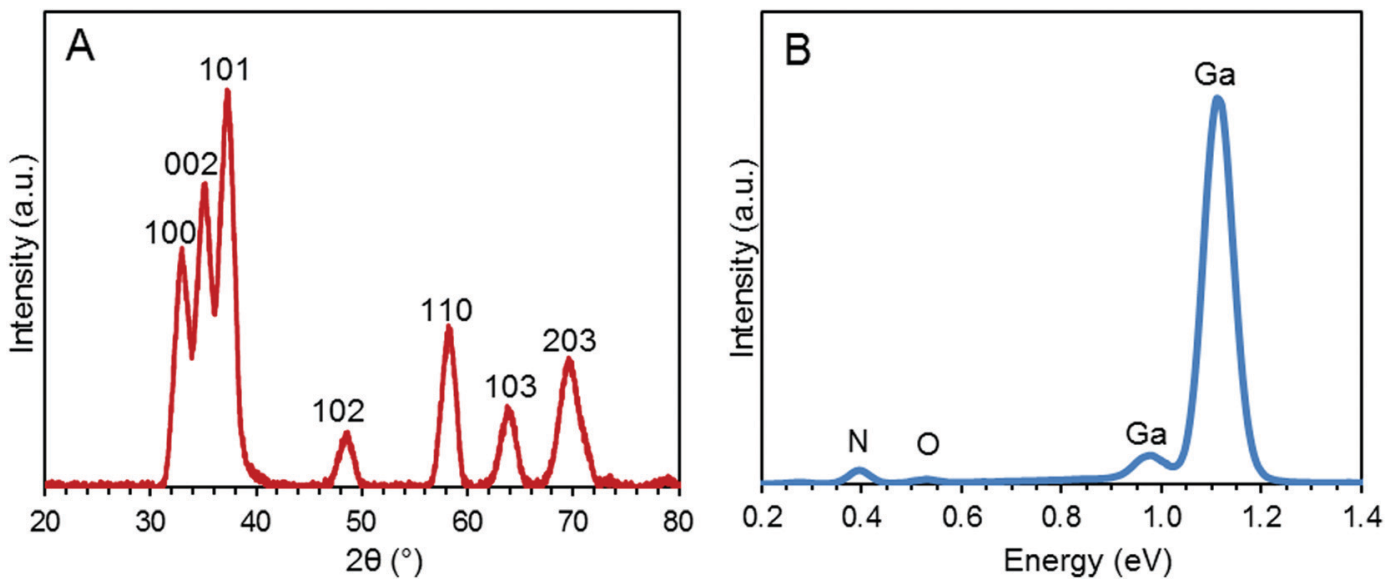

Fig. 2 (A) XRD pattern of the GaN NPs. (B) Energy-dispersive spectrum of the GaN NPs. The weight percent elemental data for nitrogen, oxygen, and gallium is $10.01,1.46$, and $88.53 \%$, respectively.

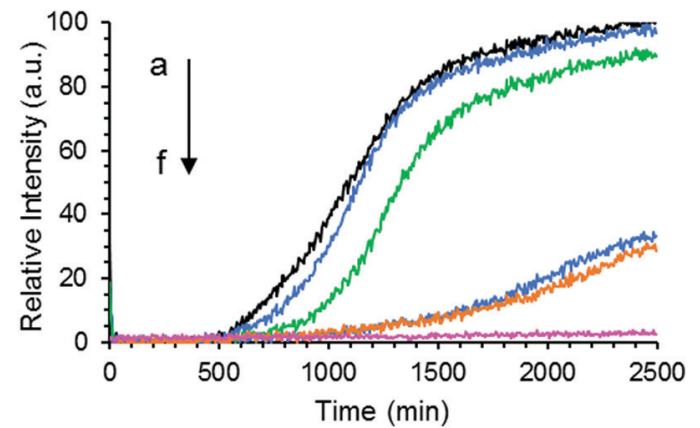

Fig. 3 Aggregation kinetics of $A \beta 40(20 \mu \mathrm{M})$ only (a), or in the presence of 47 (b), 60 (c), 67 (d), $73 \mu \mathrm{g} \mathrm{mL} \mathrm{m}^{-1}$ (e) of GaN NPs, respectively followed by ThT fluorescence. Curve $f$ is the fluorescence intensity of the sample containing $80 \mu \mathrm{g} \mathrm{mL}^{-1} \mathrm{GaN} \mathrm{NPs}$ and $20 \mu \mathrm{M}$ ThT only without $A \beta 40$.

initial baseline of the kinetic runs containing $A \beta 40$. This confirms that the observed ThT fluorescence intensity change in the A $\beta 40$ aggregation measurements is not due to direct interactions between ThT and GaN NPs.

The addition of GaN NPs markedly delays the aggregation kinetics of $A \beta 40$. In the presence of $60 \mu \mathrm{g} \mathrm{mL}^{-1}$ GaN NPs, the value of $\tau_{50}$ increases to 1227 minutes (Fig. 3 and 4), ca.18\% longer than that of $\mathrm{A} \beta 40$ alone. Increasing the GaN concentration to $73 \mu \mathrm{g} \mathrm{mL} \mathrm{mL}^{-1}$ results in a two-fold increase in $\tau_{50}$ relative to that of $A \beta 40$ in the absence of GaN NPs, up to 2197 minutes. Further increase of the GaN concentration shows smaller change in $\tau_{50}$. Furthermore, as shown in Fig. $4 \mathrm{~B}$, the $\tau_{\text {lag }}$ of the $\mathrm{A} \beta 40$ aggregation kinetics is approximately 700 minutes, and the addition of $67 \mu \mathrm{g} \mathrm{mL} \mathrm{m}^{-1} \mathrm{GaN}$ increases the $\tau_{\text {lag }}$ value to 1349 minutes. This result suggests that the presence of appropriate amounts of GaN can delay the rate of critical oligomeric nucleus formation of $\mathrm{A} \beta$. It is worth noting that the highest GaN concentration achievable in the experiments is limited by its solubility. Increasing the GaN concentration also affects the apparent growth rate constant $(k)$ of the exponential phase. For instance, the $k$ value of the kinetics in the presence
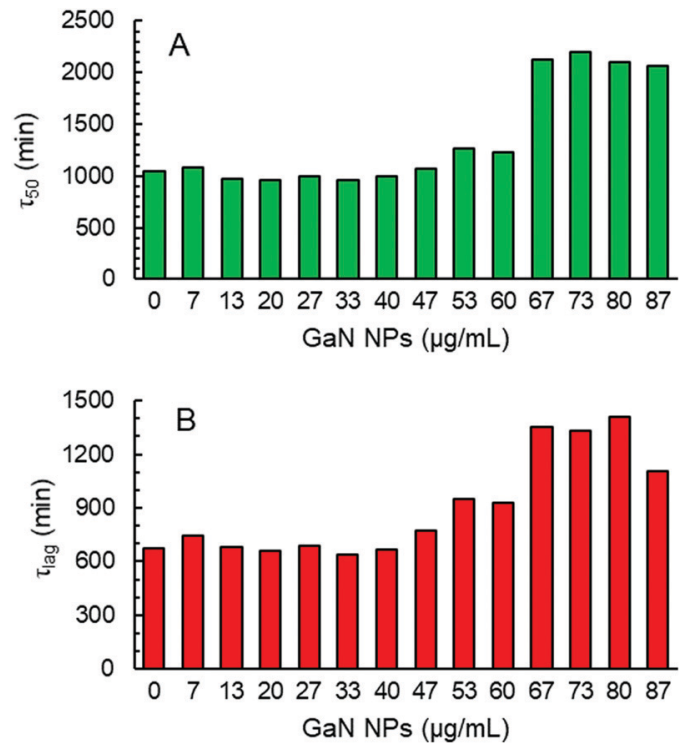

Fig. 4 (A) $\tau_{50}$ of the aggregation kinetics of $A \beta 40(20 \mu \mathrm{M})$ in the presence of different amounts of GaN NPs. (B) $\tau_{\text {lag }}$ of the aggregation kinetics of $\mathrm{A} \beta 40(20 \mu \mathrm{M})$ in the presence of different amounts of GaN NPs.

of $67 \mu \mathrm{g} \mathrm{mL}^{-1} \mathrm{GaN}$ NPs is $2.57 \times 10^{-3} \mathrm{~min}^{-1}$, which is less than half that of the kinetics of the peptide only. A larger $k$ value suggests a higher order exponential phase where growth of the fibrils occurs. ${ }^{45-49}$ The results suggest that the addition of higher amount of GaN NPs can also significantly interfere with the growth process of the amyloid fibrils, thus inhibiting the formation of amyloids.

The maximum of ThT fluorescence amplitude in $\mathrm{A} \beta$ aggregation kinetics is influenced by the addition of GaN NPs. In general, ThT fluorescence emission intensity is proportional to the amyloid fibers present, and a decrease in the intensity can be indicative of a decrease in the overall fiber content. ${ }^{50}$ As depicted in Fig. 5, increasing the GaN NP concentration lowers the ThT maximum fluorescence amplitude. These results 


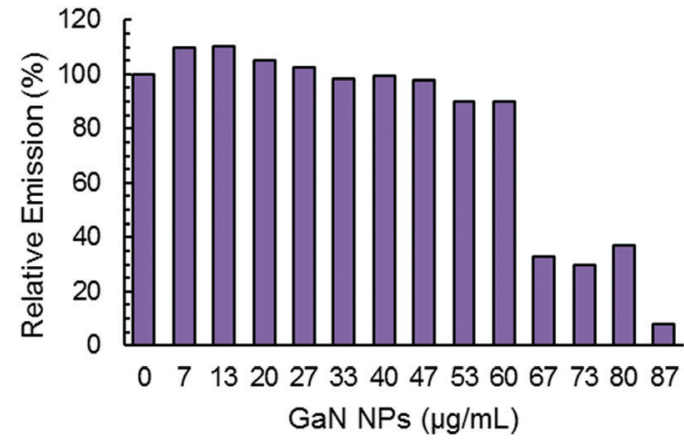

Fig. 5 Normalized maximum ThT fluorescence emission intensity during the aggregation of $\mathrm{A} \beta 40(20 \mu \mathrm{M})$ without or with different concentrations of GaN NPs.

suggest the inhibition of $A \beta 40$ fibril formation by GaN NPs. It is interesting that there is also an apparent threshold concentration value of approximately $60 \mu \mathrm{g} \mathrm{mL} \mathrm{m}^{-1}$ where the inhibition efficiency starts to increase sharply. Taken together, these results demonstrate that GaN NPs can delay the formation of the crucial nucleus in $A \beta$ aggregation and slow down the rate of $A \beta 40$ amyloid fibril formation. In addition, GaN NPs can also decrease the growth rate constant of $\mathrm{A} \beta 40$ amyloid formation.

Although a general mechanism for the underlying impact of NPs on protein fibril formation remains elusive, ${ }^{14}$ the structural characteristics of the NPs such as size, shape, and the surface properties have been demonstrated to be crucial in the interactions of the particles and proteins and the inhibition activities of NPs on protein amyloid formation. ${ }^{49,51,52}$ The inhibition activity of GaN on A $\beta 40$ aggregation likely arises from interactions between the peptide and the NPs in aqueous solution, which may be driven by interactions such as electrostatic and van der Waals interactions. The non-centrosymmetric wurtzite hexagonal structure of GaN NPs has planes consisting of anions and cations that attract each other via electrostatic forces inducing a spontaneous polarization that is larger than other materials. ${ }^{18}$ It is conceivable that this polari zation property may play an important role in the interaction of GaN and $\mathrm{A} \beta 40$ peptide, which, as a result, would prevent or decrease peptide-peptide interactions possibly by stabilizing the $\mathrm{A} \beta 40$ monomers.

\section{Inhibition of GaN NPs on Aß40 aggregation measured using CR binding}

CR has also been widely used in monitoring peptide aggregation and fibril formation. The absorption spectrum of CR peaks at around $490 \mathrm{~nm}$ ( $\pi-\pi^{*}$ transition of the azo group) in aqueous solution, ${ }^{53}$ is shifted to $c a .550 \mathrm{~nm}$ when $\mathrm{A} \beta 40$ fibrils are present. This bathochromic shift is easily seen visually where an orange red to rose change in colour is observed. We conducted an experiment using $\mathrm{CR}$ as a probe to further prove that GaN NPs can decrease the aggregation rate of $A \beta 40$ and its fibril quantity. The absorption spectra of different solutions containing $\mathrm{CR}$ alone, A $\beta 40-\mathrm{CR}$, and A $\beta 40-\mathrm{CR}-\mathrm{GaN}$ were
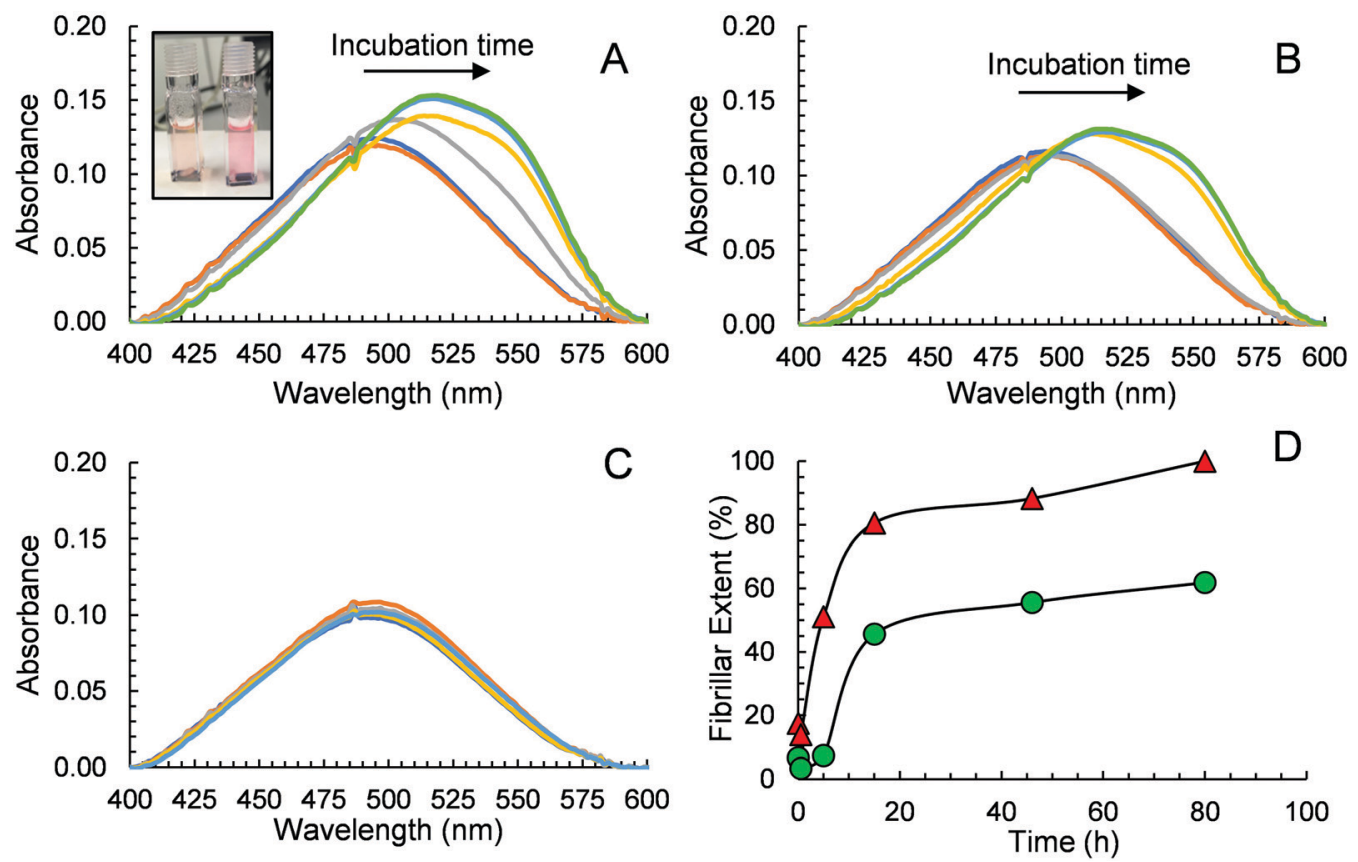

Fig. 6 Absorption spectra of $A \beta 40\left(15 \mu \mathrm{M}\right.$, containing $5 \mu \mathrm{M}$ CR) in the absence (A) or in the presence (B) of $87 \mu \mathrm{g} \mathrm{mL} \mathrm{L}^{-1} \mathrm{GaN} \mathrm{NPs}$. The spectra were measured at the incubation times of $0 \mathrm{~h}$ (dark blue), $0.5 \mathrm{~h}$ (orange), $5 \mathrm{~h}$ (gray), $15 \mathrm{~h}$ (yellow), $46 \mathrm{~h}$ (light blue), and $80 \mathrm{~h}$ (green). Inset in (A): photo of samples containing GaN-AB40 (left) and A 40 (right) showing the difference in colour after a $5 \mathrm{~h}$ incubation. (C) Absorption spectra of CR and GaN NPs only measured at the incubation times of $0 \mathrm{~h}$ (dark blue), $0.5 \mathrm{~h}$ (orange), $5 \mathrm{~h}$ (gray), $15 \mathrm{~h}$ (yellow), $46 \mathrm{~h}$ (light blue), and $80 \mathrm{~h}$ (green). (D) Quantitative evaluation of fibrillar extent during the aggregation of A 340 in the absence (red triangles) or in the presence (green circles) of GaN NPs (87 $\mu$ g $\mathrm{mL}^{-1}$ ). A baseline correction due to scattering was applied to each spectrum before reading the absorbance values. The fibrillar extent values are relative to the maximum $A \beta 40$ fibrillar concentration at $80 \mathrm{~h}$ for an $A \beta 40$ solution in the absence of GaN NPs. 
measured at different times of incubation. The solution containing only $A \beta 40$ shows an initial absorption spectrum that resembles the one of $\mathrm{CR}$ with a broad band peak with a maximum at $490 \mathrm{~nm}$ (Fig. 6A). After $\sim 5$ hours, the formation of $A \beta 40$ amyloids is indicated by the absorbance increase in the 520-550 nm region (Fig. 6A). The absorbance in this region increases with time reaching a plateau after $\sim 20$ hours. When $\mathrm{A} \beta 40$ is incubated in the presence of GaN NPs $\left(87 \mu \mathrm{g} \mathrm{mL}^{-1}\right)$, the intensity change of the absorbance at $541 \mathrm{~nm}$, characteristic for $\mathrm{A} \beta 40$ aggregation, is slower than that of $\mathrm{A} \beta 40$ alone (Fig. $6 \mathrm{~B} v s$. $6 \mathrm{~A})$. This result further indicates the inhibition activity of GaN NPs on A $\beta 40$ aggregation. To rule out the possibility that CR can directly interact with GaN NPs and cause a change in the absorption, we also performed control experiments in the absence of $A \beta 40$. The results show that the CR-GaN NPs absorption spectrum does not change with incubation time (Fig. 6C), hence corroborating that the spectral changes are due to the formation of $A \beta 40$ fibrils.

Quantitative fibrillar formation was also studied using CR as a probe. ${ }^{54}$ The concentration of $\mathrm{A} \beta$ fibrils at certain times, in $\mu \mathrm{g} \mathrm{mL} \mathrm{m}^{-1}$, was estimated from CR binding where $\left[\mathrm{A} \beta 40_{\text {fibrils }}\right]_{t}=$ $\left(\mathrm{A}_{541 \text { mix }} / 4780\right)-\left(\mathrm{A}_{403 \text { mix }} / 6830\right)-\left(\mathrm{A}_{403 \mathrm{CR}} / 8620\right)$ where $\mathrm{A}_{541 \text { mix }}$ and $\mathrm{A}_{403 \mathrm{mix}}$ are the absorbances of the solutions containing $\mathrm{A} \beta 40$ or $\mathrm{A} \beta 40-\mathrm{GaN}$ at 541 and $403 \mathrm{~nm}$, respectively, and $\mathrm{A}_{403 \mathrm{CR}}$ is the absorbance of the solution containing $\mathrm{CR}$ alone under the same experimental incubation time. ${ }^{54}$ The results are shown in Fig. 6D. The data shows that the lag phase is around 4 hours for $\mathrm{A} \beta 40$ in the presence of $\mathrm{GaN}\left(87 \mu \mathrm{g} \mathrm{mL} \mathrm{m}^{-1}\right)$, which is approximately three times longer than that in the absence of GaN. In addition, the presence of GaN NPs reduces the fibrillar content by up to $62 \%$ after 80 hours of incubation. These results are in accord with what observed in the ThT kinetics study.

\section{Inhibition of GaN NPs on Aß40 aggregation confirmed using turbidity and imaging studies}

Turbidity measurements were also performed to monitor A $\beta 40$ aggregation as it is well-known that protein aggregate formation leads to an increase in the sample absorbance at $600 \mathrm{~nm} .{ }^{40}$ The absorbance intensity at $600 \mathrm{~nm}$ was monitored as a function of time for $A \beta 40$ aggregation in the absence and presence of GaN NPs at $87 \mu \mathrm{g} \mathrm{mL}^{-1}$. As shown in Fig. 7, the presence of GaN NPs significantly decreases the fibril formation kinetics, consistent with both the ThT and CR results. The inhibitory activity of the particles on A $\beta 40$ fibrillogenesis was further confirmed using SEM imaging (Fig. 8). SEM images were acquired using the samples from the $A \beta 40$ aggregation kinetics study in the absence or presence of GaN NPs. In the absence of GaN NPs, A $\beta 40$ aggregated to form fibrils of a few micrometers long and produced large conglomerates. In contrast, in the presence of GaN NPs, the number of fibrils was dramatically reduced and no large clusters were observed. Taken together, these results corroborate that GaN NPs are an effective inhibitor of $A \beta 40$ amyloid fibril formation.

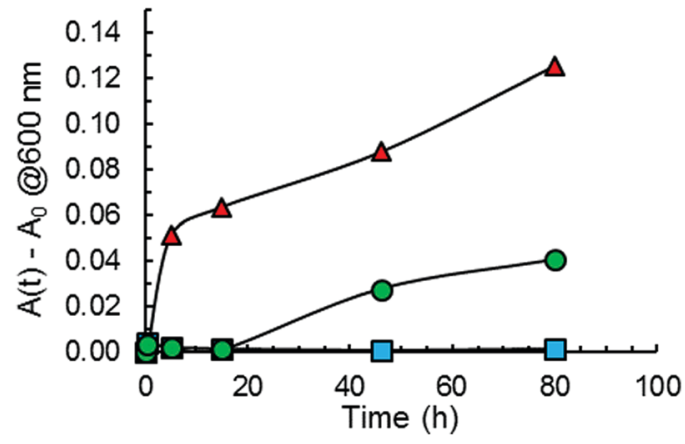

Fig. 7 Turbidity curves for $A \beta 40$ aggregation in the absence (red triangles) or in the presence of $87 \mu \mathrm{g} \mathrm{mL}^{-1}$ GaN NPs (green circles) measured by monitoring the absorbance at $600 \mathrm{~nm}$. A curve for the solution containing GaN NP and CR alone (blue squares) incubated in parallel is also shown. Solid lines are to guide the reader.
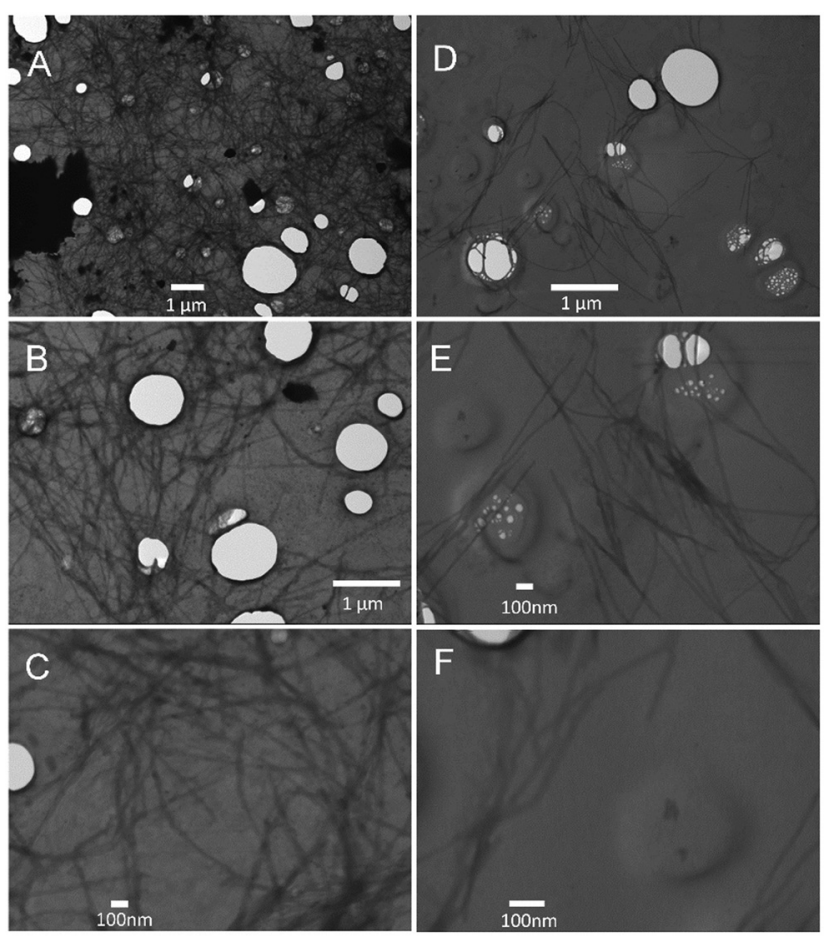

Fig. 8 SEM images of $A \beta 40(20 \mu M)$ acquired after the aggregation kinetics measurement using ThT fluorescence emission. Left: SEM images of $A \beta 40$ only measured at different magnifications: (A) $10000 \times$, (B) $20000 \times$, and (C) $50000 \times$. Right: SEM images of $A \beta 40$ in the presence of $87 \mu \mathrm{g} \mathrm{mL}^{-1} \mathrm{GaN}$ NPs measured at different magnifications: (D) $20000 \times$, (E) $50000 \times$, and (F) $100000 \times$

\section{Conclusions}

In summary, we studied the effect of GaN NPs on A $\beta 40$ amyloid fibril formation using a variety of approaches including ThT fluorescence, CR absorbance, turbidity, and SEM imaging. Our results show that the presence of GaN NPs significantly delays the lag time of $A \beta 40$ aggregation, indicating its inhibiting activity on crucial oligomeric nucleus formation of the peptide. 
Also, the results show that GaN NPs can slow down the amyloid fibril elongation rate in the amyloid growth phase of the aggregation kinetics. Considering that the non-centrosymmetric wurtzite hexagonal structure of GaN NPs contains planes consisting of anions and cations that induce strong spontaneous polarization, it is plausible that this polarization characteristic of the particle can provoke a stronger interaction between the NPs and A $\beta 40$ peptide and thus decrease intermolecular interactions among the peptide monomers to form amyloids. Future studies on modification of the surface characteristics of gallium nanoparticles to enhance solubility and selectivity may lead to the discovery of new NP inhibitors with high biocompatibility and inhibition efficiency.

\section{Author contributions}

KMT, ASD, ERS, NVFC, and AM performed the experiments. IR, $\mathrm{DD}$ and RO conceived and wrote the paper.

\section{Conflicts of interest}

The authors declare no competing financial interests.

\section{Acknowledgements}

This work was supported by NSF-DMR-2122102. KT and ES acknowledge support from the NIH-UPRH-MARC-T34GM 008156 undergraduate student training in academic research program. The authors acknowledge Dr. Feng Gai (University of Pennsylvania) for valuable discussions. We also acknowledge Jamie Ford for obtaining the SEM images at the Singh Center for Nanotechnology at the University of Pennsylvania, which is supported by the NSF National Nanotechnology Coordinated Infrastructure Program under grant NNCI-1542153. DD acknowledges financial support from the National Institutes of Health (R15GM116006) and the Alzheimer's Association (AARG-17-531423).

\section{References}

1 A. K. Sahoo, J. Dandapat, U. C. Dash and S. Kanhar, J. Ethnopharmacol., 2018, 215, 42-73.

2 J. Cummings, G. Lee, A. Ritter and K. Zhong, Alzheimer's Dementia, 2018, 4, 195-214.

3 S. K. Singh, S. Srivastav, A. K. Yadav, S. Srikrishna and G. Perry, Oxid. Med. Cell. Longevity, 2016, 2016, 7361613.

4 P. H. Nguyen, A. Ramamoorthy, B. R. Sahoo, J. Zheng, P. Faller, J. E. Straub, L. Dominguez, J.-E. Shea, N. V. Dokholyan, A. De Simone, B. Ma, R. Nussinov, S. Najafi, S. T. Ngo, A. Loquet, M. Chiricotto, P. Ganguly, J. McCarty, M. S. Li, C. Hall, Y. Wang, Y. Miller, S. Melchionna, B. Habenstein, S. Timr, J. Chen, B. Hnath, B. Strodel, R. Kayed, S. Lesné, G. Wei, F. Sterpone, A. J. Doig and P. Derreumaux, Chem. Rev., 2021, 121, 2545-2647.
5 B. R. Sahoo, S. J. Cox and A. Ramamoorthy, Chem. Commun., 2020, 56, 4627-4639.

6 E. E. Cawood, T. K. Karamanos, A. J. Wilson and S. E. Radford, Biophys. Chem., 2021, 268, 106505.

7 M. I. Ivanova, Y. Lin, Y.-H. Lee, J. Zheng and A. Ramamoorthy, Biophys. Chem., 2021, 269, 106507.

8 P. Williams, A. Sorribas and M.-J. R. Howes, Nat. Prod. Rep., 2011, 28, 48-77.

9 C. Cabaleiro-Lago, F. Quinlan-Pluck, I. Lynch, S. Lindman, A. M. Minogue, E. Thulin, D. M. Walsh, K. A. Dawson and S. Linse, J. Am. Chem. Soc., 2008, 130, 15437-15443.

10 D. J. Selkoe, Science, 1997, 275, 630-631.

11 R. Liu, J. Yang, L. Liu, Z. Lu, Z. Shi, W. Ji, J. Shen and X. Zhang, Adv. Sci., 2020, 7, 1901555.

12 A. Binda, C. Murano and I. Rivolta, Int. J. Nanomed., 2020, 15, 6113-6135.

13 G. Altinoglu and T. Adali, Curr. Drug Targets, 2020, 21, 628-646.

14 T. John, A. Gladytz, C. Kubeil, L. L. Martin, H. J. Risselada and B. Abel, Nanoscale, 2018, 10, 20894-20913.

15 J. Gupta, M. T. Fatima, Z. Islam, R. H. Khan, V. N. Uversky and P. Salahuddin, Int. J. Biol. Macromol., 2019, 130, 515-526.

16 Y.-H. Liao, Y.-J. Chang, Y. Yoshiike, Y.-C. Chang and Y.-R. Chen, Small, 2012, 8, 3631-3639.

17 T. Yin, L. Yang, Y. Liu, X. Zhou, J. Sun and J. Liu, Acta Biomater., 2015, 25, 172-183.

18 X. Li and X. Liu, Nanoscale, 2017, 9, 7320-7341.

19 D. Franke, A. Luisa da Rosa, M. Lorke and T. Frauenheim, Phys. Status Solidi B, 2019, 256, 1800455.

20 C. M. Foster, R. Collazo, Z. Sitar and A. Ivanisevic, Langmuir, 2013, 29, 8377-8384.

21 G. Steinhoff, O. Purrucker, M. Tanaka, M. Stutzmann and M. Eickhoff, Adv. Funct. Mater., 2003, 13, 841-846.

22 T. H. Young and C. R. Chen, Biomaterials, 2006, 27, 3361-3367.

23 T. Braniste, I. Tiginyanu, T. Horvath, S. Raevschi, S. Cebotari, M. Lux, A. Haverich and A. Hilfiker, Beilstein J. Nanotechnol., 2016, 7, 1330-1337.

24 T. Braniste, I. Tiginyanu, T. Horvath, S. Raevschi, B. Andree, S. Cebotari, E. C. Boyle, A. Haverich and A. Hilfiker, Nanoscale Res. Lett., 2017, 12, 486.

25 M. Hofstetter, J. Howgate, M. Schmid, S. Schoell, M. Sachsenhauser, D. Adigüzel, M. Stutzmann, I. D. Sharp and S. Thalhammer, Biochem. Biophys. Res. Commun., 2012, 424, 348-353.

26 S. A. Jewett, M. S. Makowski, B. Andrews, M. J. Manfra and A. Ivanisevic, Acta Biomater., 2012, 8, 728-733.

27 P. Sahoo, P. S. Murthy, S. Dhara, V. P. Venugopalan, A. Das and A. K. Tyagi, J. Nanopart. Res., 2013, 15, 1841.

28 S. R. Choi, B. E. Britigan and P. Narayanasamy, Antimicrob. Agents Chemother., 2019, 63, e02643-02618.

29 L. E. Bain, M. P. Hoffmann, I. Bryan, R. Collazo and A. Ivanisevic, Nanoscale, 2015, 7, 2360-2365.

30 Y. Chen, N. Jyoti and J. Kim, Appl. Phys. A, 2011, 102, 517-519.

31 H.-L. Li, R.-J. Xie, N. Hirosaki, B. Dierre, T. Sekiguchi and Y. Yajima, J. Am. Ceram. Soc., 2008, 91, 1711-1714. 
32 J. L. Robles-Garcia, A. Melendez, D. Yates, J. J. SantiagoAviles, I. Ramos and E. M. Campo, Proc. SPIE, 2011, 8036, 80360F/80361-80360F/80367.

33 A. Melendez, K. Morales, I. Ramos, E. Campo and J. J. Santiago-Aviles, Proc. SPIE, 2009, 7402, 740210/ 740211-740210/740216.

34 E. M. Campo, J. Poplawsky, A. Melendez, J. L. Robles-Garcia, I. Ramos, D. Yates, J. E. Fischer and J. J. Santiago-Aviles, RSC Adv., 2014, 4, 2634-2639.

35 U. Holzwarth and N. Gibson, Nat. Nanotechnol., 2011, 6, 534.

36 N. P. Cook, V. Torres, D. Jain and A. A. Martí, J. Am. Chem. Soc., 2011, 133, 11121-11123.

37 H. Liu, R. Lantz, P. Cosme, N. Rivera, C. Andino, W. G. Gonzalez, A. C. Terentis, E. P. Wojcikiewicz, R. Oyola, J. Miksovska and D. Du, Chem. Commun., 2015, 51, 7000-7003.

38 L. Nielsen, R. Khurana, A. Coats, S. Frokjaer, J. Brange, S. Vyas, V. N. Uversky and A. L. Fink, Biochemistry, 2001, 40, 6036-6046.

39 S. Lee, E. J. Fernandez and T. A. Good, Protein Sci., 2007, 16, 723-732.

40 J. Jayamani, G. Shanmugam and E. R. Azhagiya Singam, RSC Adv., 2014, 4, 62326-62336.

41 S.-H. Wang, X.-Y. Dong and Y. Sun, Biochem. Eng. J., 2012, 63, 38-49.

42 M. J. Hore, X. Ye, J. Ford, Y. Gao, J. Fei, Q. Wu, S. J. Rowan, R. J. Composto, C. B. Murray and B. Hammouda, Nano Lett., 2015, 15, 5730-5738.
43 E. Arad, H. Green, R. Jelinek and H. Rapaport, J. Colloid Interface Sci., 2020, 573, 87-95.

44 J. T. Pedersen and N. H. H. Heegaard, Anal. Chem., 2013, 85, 4215-4227.

45 L. Hong, X. Qi and Y. Zhang, J. Phys. Chem. B, 2012, 116, 6611-6617.

46 A. K. Buell, Biochem. J., 2019, 476, 2677-2703.

47 T. C. Michaels, H. W. Lazell, P. Arosio and T. P. Knowles, J. Chem. Phys., 2015, 143, 054901.

48 P. Arosio, T. P. Knowles and S. Linse, Phys. Chem. Chem. Phys., 2015, 17, 7606-7618.

49 K. Shezad, K. Zhang, M. Hussain, H. Dong, C. He, X. Gong, X. Xie, J. Zhu and L. Shen, Langmuir, 2016, 32, 8238-8244.

50 S. J. Cox, B. Lam, A. Prasad, H. A. Marietta, N. V. Stander, J. G. Joel, B. R. Sahoo, F. Guo, A. K. Stoddard, M. I. Ivanova and A. Ramamoorthy, Biochemistry, 2020, 59, 2249-2258.

51 G. Gao, M. Zhang, D. Gong, R. Chen, X. Hu and T. Sun, Nanoscale, 2017, 9, 4107-4113.

52 M. Lundqvist, J. Stigler, G. Elia, I. Lynch, T. Cedervall and K. A. Dawson, Proc. Natl. Acad. Sci. U. S. A., 2008, 105, 14265-14270.

53 K. Yokoyama, A. Fischer, A. R. Amori, D. R. Welchons and R. E. McKnight, J. Biophys. Chem., 2010, 1, 153-163.

54 W. E. Klunk, R. F. Jacob and R. P. Mason, Anal. Biochem., 1999, 266, 66-76. 